\title{
Tsunami run-up heights of the 2004 off the Kii peninsula earthquakes
}

\author{
Nobuaki Koike ${ }^{1}$, Tomoyuki Takahashi ${ }^{2}$, Kentaro Imai ${ }^{2}$, Yuichiro Tanioka ${ }^{3}$, Yuichi Nishimura ${ }^{3}$, Kenji Harada ${ }^{4}$, \\ Shingo Suzuki ${ }^{4}$, Koji Fujima ${ }^{5}$, Yoshinori Shigihara ${ }^{5}$, Yuichi Namegaya ${ }^{6}$, and Shunichi Koshimura ${ }^{7}$ \\ ${ }^{1}$ Department of Civil and Environmental Engineering, Wakayama National College of Technology, 77 Noshima, \\ Nada-cho, Gobo, Wakayama 644-0023, Japan \\ ${ }^{2}$ Department of Civil and Environmental Engineering, Faculty of Engineering and Resource Science, Akita University, \\ 1-1 Tegatagakuen, Akita 010-8502, Japan \\ ${ }^{3}$ Institute of Seismology and Volcanology, Hokkaido University, N10W8 Kita-ku, Sapporo 060-0810, Japan \\ ${ }^{4}$ Disaster Prevention Research Institute, Kyoto University, Gokasho, Uji, Kyoto 611-0011, Japan \\ ${ }^{5}$ National Defense Academy in Japan, 1-10-20 Hashirimizu, Yokosuka, Kanagawa 239-8686, Japan \\ ${ }^{6}$ Earthquake Research Institute, University of Tokyo, 1-1-1 Yayoi, Bunkyo-ku, Tokyo 113-0032, Japan \\ ${ }^{7}$ Disaster Reduction and Human Renovation Institution, 1-5-2 Wakinohama kaigan-dori, Chuo-ku, Kobe 651-0073, Japan
}

(Received November 30, 2004; Revised February 24, 2005; Accepted February 25, 2005)

\begin{abstract}
A tsunami height survey was conducted immediately after the 2004 off the Kii peninsula earthquakes. Results of the survey show that the largest tsunami height was about $4.6 \mathrm{~m}$ locally at Kiho-cho, Mie prefecture. Numerical simulation of the tsunami due to the earthquake was carried out using the model parameters estimated by NIED. The distribution pattern of the observed tsunami heights along the coast cannot be explained by the computed heights, because the model equation is linear long-wave theory and the run-up computations with a finer grid system are not included in this simulation. In order to explain tsunami run-up heights, it is necessary that the non-linear and run-up computation model should be used with a finer grid system.
\end{abstract}

Key words: The 2004 off the Kii peninsula earthquakes, tsunami height survey, tsunami numerical simulation.

\section{Introduction}

On 5 September 2004, two earthquakes occurred at sea off the Kii peninsula in Japan. The Japan Meteorological Agency (JMA) estimated the source parameters as follows: for the foreshock: origin time, 19:07 (JST); epicenter, $33.2 \mathrm{~N}$ degrees, 136.9E degrees; depth $10 \mathrm{~km}$; JMA magnitude, $\mathbf{M}_{j}$ 7.1. For the mainshock: origin time, 23:57 (JST); epicenter, 33.2N degrees, 137.1E degrees; depth, $10 \mathrm{~km}$; JMA magnitude 7.4. The seismic moment of the second earthquake was $8.81 \times 10^{19} \mathrm{Nm}$, or $\mathrm{M}_{\mathrm{w}} 7.3$ estimated by the National Research Institute for Earth Science and Disaster Prevention (NIED) in Japan. Immediately after the earthquakes, tsunami surveys were conducted by researchers from all over Japan. Several survey teams covered all the coasts of the eastern Kii peninsula. In this paper, observed tsunami run-up heights of the 2004 earthquakes off the Kii peninsula are compiled. The result of a numerical simulation of the 2004 tsunami is compared with the observed tsunami run-up heights.

\section{Tsunami Height Survey}

A tsunami assessment was conducted immediately after the earthquakes. The survey was compiled by 7 September, two days after the earthquakes. A quick survey is particularly important for a moderate tsunami of which the run-up heights are less than $2 \mathrm{~m}$. Most of the deposits from such a moderate tsunami existed in the surf zone, although they

Copy right(C) The Society of Geomagnetism and Earth, Planetary and Space Sciences (SGEPSS); The Seismological Society of Japan; The Volcanological Society of Japan; The Geodetic Society of Japan; The Japanese Society for Planetary Sciences; TERRAPUB. were quickly disturbed by high waves. The results of the tsunami height survey are shown in Fig. 1 and Table 1. The heights are measured from various objects that the tsunami left behind or from eyewitness accounts. The observed tsunami heights due to the 2004 earthquakes in Table 1 are calculated from the tide level at the time of the maximum tsunami. The largest tsunami height was about $4.6 \mathrm{~m}$ locally at Kiho-cho, Mie. It seems that the tsunami height was higher there because of the shallow slope. Photo 1 shows the place where the tsunami height is the largest, at Kihocho.

\section{Numerical Simulation of the Tsunami}

The model parameters are estimated by NIED (2004) (see Table 2). The vertical seafloor-displacement was computed using Okada's (1985) equations and used as an initial condition for tsunami numerical computation (see Fig. 3). A finite-difference computation of the linear long-wave equations was carried out. The grid size was $1 \mathrm{~km}$. The time step of the computation was $1 \mathrm{sec}$ so as to satisfy the stability condition. The results of the tsunami computation are shown in Fig. 2 along with the observed tsunami heights. The computed heights largely underestimate the observed ones because the run-up computation using a finer grid system is not included in this simulation. The distribution pattern of the observed tsunami heights along the coast cannot be explained by the computed heights.

\section{Conclusion}

A tsunami height survey was conducted immediately after the 2004 off the Kii peninsula earthquakes. The results 

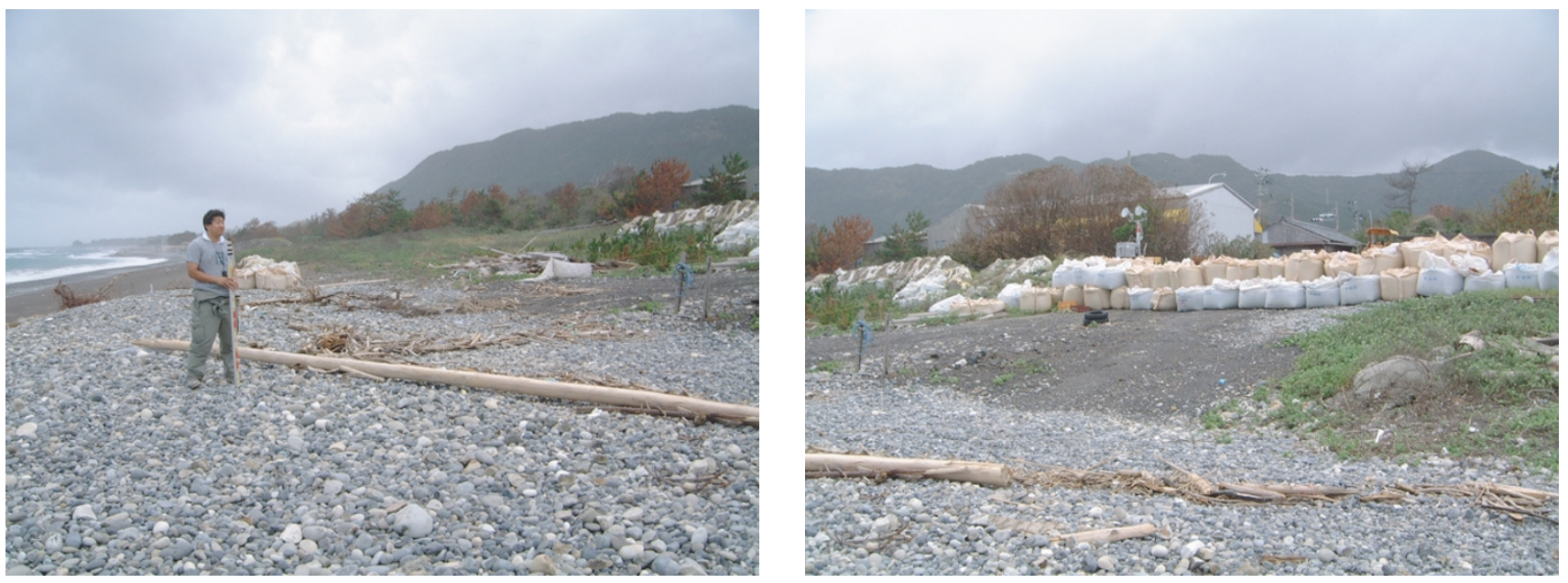

Photo 1. Two photos when tsunami run-up heights were measured at Kiho-cho, Mie Prefecture.

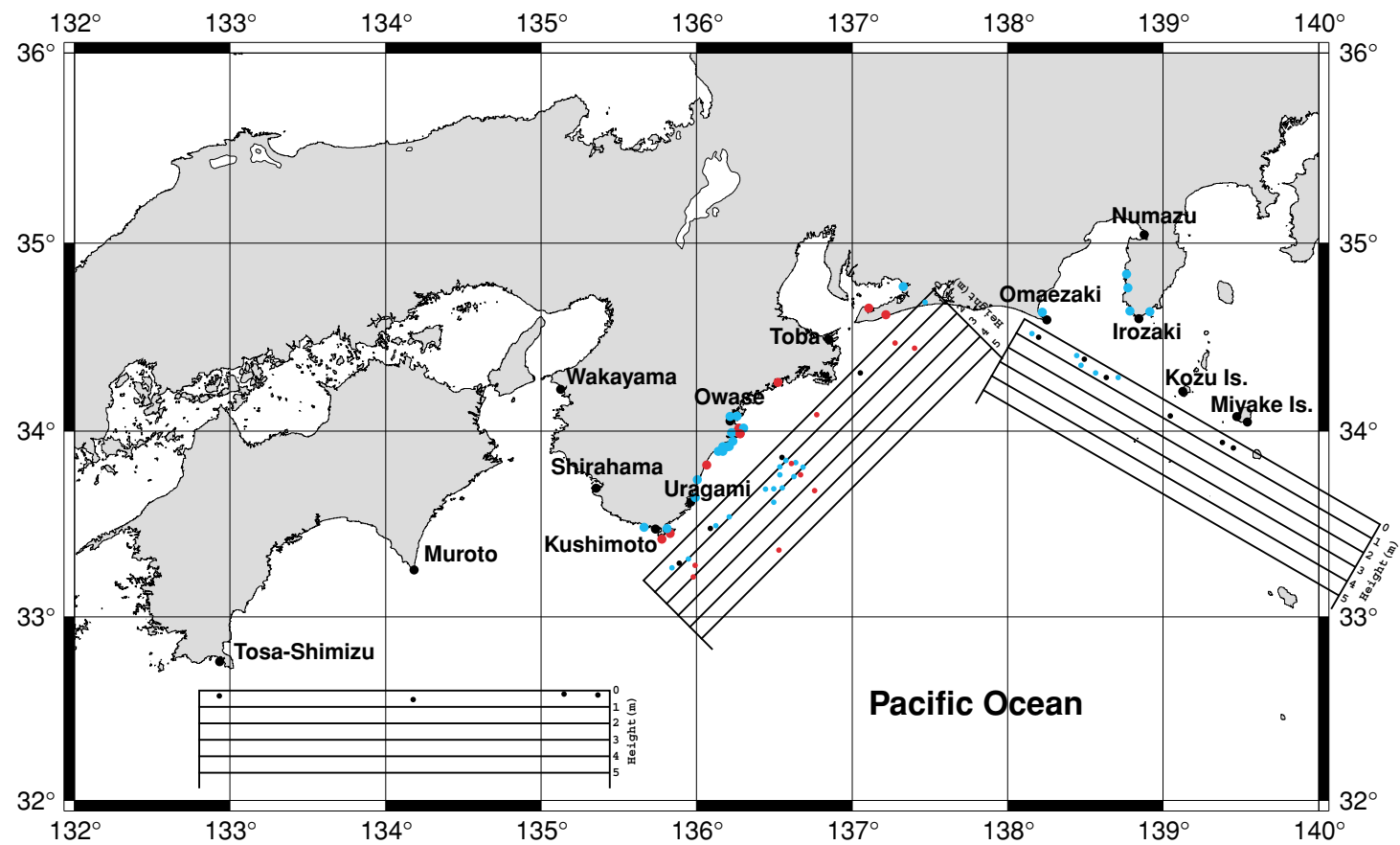

Fig. 1. The measured tsunami heights for the 2004 off the Kii peninsula earthquakes.

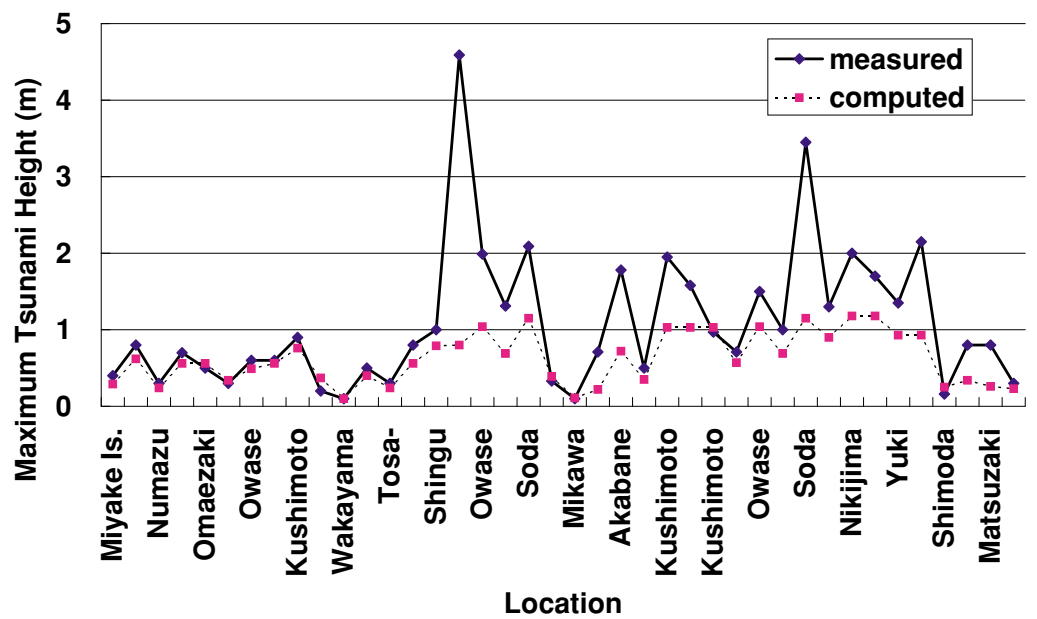

Fig. 2. Comparison of the measured and computed tsunami heights for the 2004 off the Kii peninsula earthquakes. 
Table 1. Tsunami height survey results.

\begin{tabular}{|c|c|c|c|}
\hline Survey point & Latitude (N) & Longitude (E) & Tsunami height $(\mathrm{m})$ (corrected from tide) \\
\hline Miyake Is. (tide gauge) & 3403 & 13933 & 0.4 \\
\hline Kozu Is. (tide gauge) & & & 0.8 \\
\hline Chichi Is. (tide gauge) & 2706 & 14211 & 0.4 \\
\hline Numazu (tide gauge) & 3501 & 13853 & 0.3 \\
\hline Irozaki (tide gauge) & 3437 & 13851 & 0.7 \\
\hline Omaezaki (tide gauge) & 3437 & 13813 & 0.5 \\
\hline Toba (tide gauge) & 3429 & 13649 & 0.3 \\
\hline Owase (tide gauge) & 3405 & 13612 & 0.6 \\
\hline Uragami (tide gauge) & 3333 & 13554 & 0.6 \\
\hline Kushimoto (tide gauge) & 3329 & 13546 & 0.9 \\
\hline Shirahama (tide gauge) & 3341 & 13523 & 0.2 \\
\hline Wakayama (tide gauge) & 3413 & 13509 & 0.1 \\
\hline Muroto (tide gauge) & 3316 & 13410 & 0.5 \\
\hline Tosa-shimizu (tide gauge) & 3247 & 13258 & 0.3 \\
\hline Katsuura (in the port) & 333733 & 1355643 & 0.8 \\
\hline Shingu (river mouth) & 334322 & 1360033 & 1.0 \\
\hline Kiho & 334609 & 1360145 & 4.59 \\
\hline Owase (in the port) & 340420 & 1361210 & 1.99 \\
\hline Kuki (Owase city) & 340102 & 1361653 & 1.31 \\
\hline Soda (Owase city) & 335956 & 1361325 & 2.09 \\
\hline Yoshizu & 341633 & 1363007 & 0.33 \\
\hline Mikawa (in the port) & & & 0.1 \\
\hline Akabane (in the port) & & & 1.78 \\
\hline Omaezaki (in the port) & & & 0.5 \\
\hline Kushimoto (in the port) & 332647 & 1354622 & 1.95 \\
\hline Kushimoto & 332652 & 1354724 & 1.58 \\
\hline Kushimoto & 332647 & 1354622 & 0.97 \\
\hline Tanami (Kushimoto town) & 332907 & 1354622 & 0.71 \\
\hline Owase (in the port) & 340439 & 1361220 & 1.50 \\
\hline Kuki (Owase city) & 340052 & 1361509 & 1.00 \\
\hline Soda (Owase city) & 335952 & 1361535 & 3.45 \\
\hline Atashika (Kumano city) & 335528 & 1360858 & 1.30 \\
\hline Nikijima (Kumano city) & 335616 & 1361050 & 2.00 \\
\hline Nikijima (Kumano city) & 335621 & 1361055 & 1.70 \\
\hline Yuki (Kumano city) & 335534 & 1361021 & 1.35 \\
\hline Yuki (Kumano city) & 335535 & 1361026 & 2.15 \\
\hline Shimoda & 343644 & 1384939 & 0.80 \\
\hline Matsuzaki & 344500 & 1384641 & 0.80 \\
\hline Kamo & 344922 & 1384641 & 0.30 \\
\hline
\end{tabular}

Table 2. Model parameters used for numerical computation.

\begin{tabular}{cccccccc}
\hline Longitude (deg.) & Latitude (deg.) & $\mathrm{L}(\mathrm{km})$ & $\mathrm{W}(\mathrm{km})$ & Strike (deg.) & Dip (deg.) & Slip(deg.) & Dislocation $(\mathrm{m})$ \\
\hline 33.2 & 137.1 & 60 & 30 & 277 & 52 & 96 & 1.8 \\
\hline
\end{tabular}




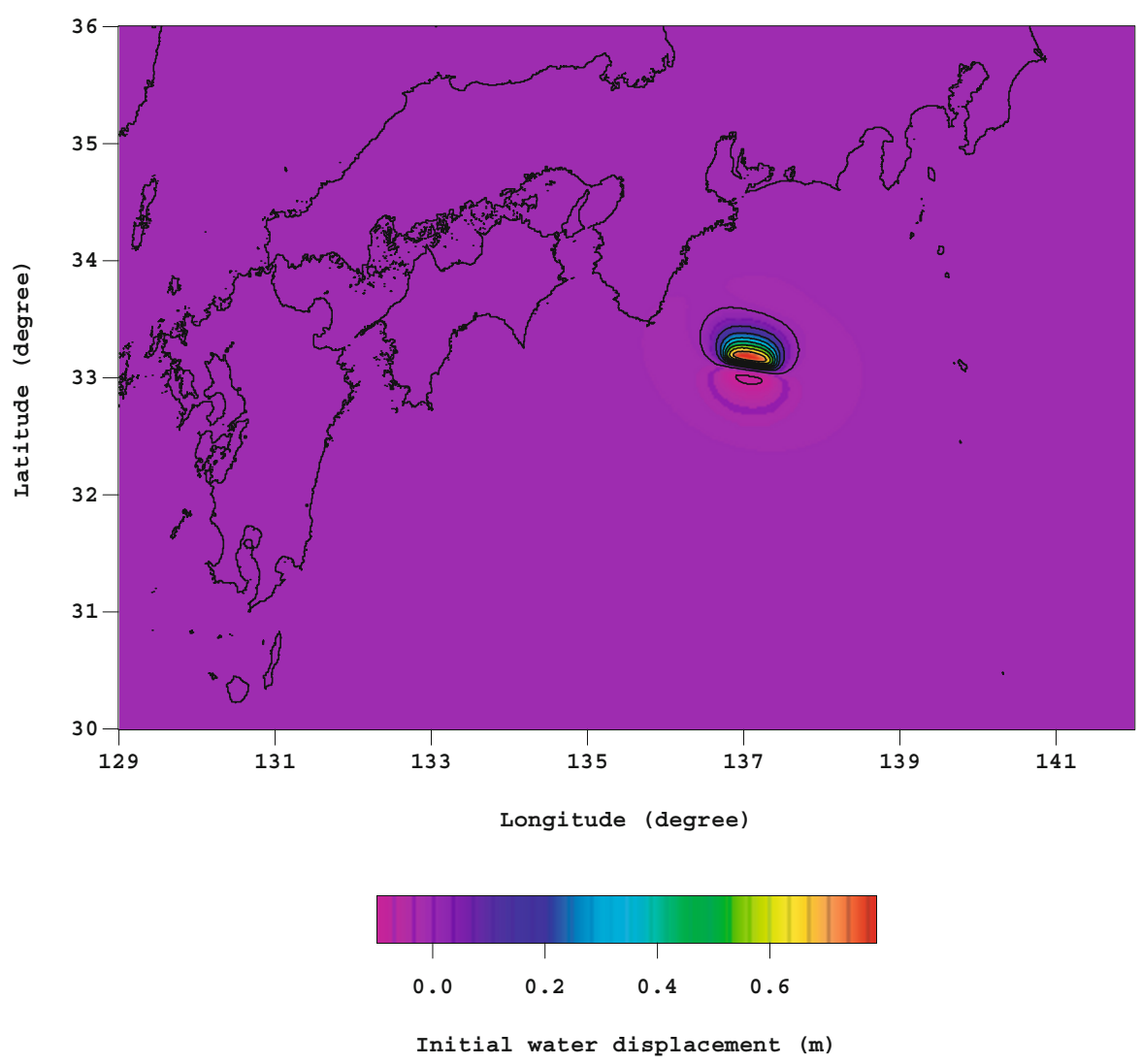

Fig. 3. Initial water displacement by model parameters of Table 2.

of the survey revealed that the run-up heights cannot be explained by computation using the linear theory and a large grid system. It seems that the heights are affected by the non-linear effect and a mild slope.

Acknowledgments. We would like to thank the tsunami and coastal researchers from all over Japan.

\section{References}

Okada, Y., Surface deformation due to shear and tensile faults in a halfspace, Bull. Seismol. Soc. Am., 75, 1135-1154, 1985.

Research Institute for Earth Science and Disaster Prevention (NIED), http: //www.fnet.bosai.go.jp/freesia/event/tdmt/20040905235800/update1/ index.html, 2004.

Satake, K. et al., Tsunami source of the 2004 off the Kii Peninsula earthquakes inferred from offshore tsunami and coastal tide gauges, Earth Planets Space, 57, this issue, 173-178, 2005.

Yamanaka, EIC Seismological Note No. 152: Offshore Southeast of the Kii Peninsula Earthquakes, http://www.eri.u-tokyo.ac.jp/sanchu/ Seismo_Note/2004/EIC152.html, 2004 (in Japanese).

N. Koike (e-mail: koikenob@wakayama-nct.ac.jp), T. Takahashi, K. Imai, Y. Tanioka, Y. Nishimura, K. Harada, S. Suzuki, K. Fujima, Y. Shigihara, Y. Namegaya, and S. Koshimura 